ЭКОЛОГИЧЕСКАЯ СРЕДА

В КОНТЕКСТЕ РАЗВИТИЯ

СОЦИАЛЬНО-

ИНВЕСТИЦИОННОЙ МОДЕЛИ

УПРАВЛЕНИЯ РОССИЙСКИМИ

РЕГИОНАМИ:

ПОТЕНЦИАЛЬНЫЕ

ВОЗМОЖНОСТИ И РИСКИ ${ }^{1}$

(C) 2021 г.

К. В. Воденко *,

O. Е. Лабадзе *

* Южно-Российский государственный политехнический университет (НПИ)

имени М.И. Платова,

2. Новочеркасск, Россия

Цель исследования определяется как изучение внешних и внутренних факторов, социально-практических запросов в российском обществе на развитие оптимальной экологической среды как необходимого условия консолидации регионального пространства.

\begin{abstract}
Методология исследования основана на междисциплинарных исследовательских процедурах, интегрирующих достижения в области философии, социологии, экологии и теории управления.
\end{abstract}

Результаты исследования. В представленной статье актуализируются вопросы социально-инвестиционного развития российских регионов в контексте экологической среды. На основании современных экософских представлений об экологической среде

\section{ECOLOGICAL ENVIRONMENT IN THE CONTEXT OF SOCIAL AND INVESTMENT DEVELOPMENT OF RUSSIAN REGIONS: POTENTIAL OPPORTUNITIES AND RISKS}

\author{
K. V. Vodenko *, \\ O. E. Labadze * \\ * Platov South-Russian \\ State Polytechnic \\ University (NPI), \\ Novocherkassk, Russia
}

Objective of the study is the examination of external and internal factors, social and practical demands in Russian society for the development of an optimal ecological environment as a necessary condition for the consolidation of the regional space.

The methodology of the research is based on interdisciplinary research procedures integrating advances in philosophy, sociology, ecology and management theory.

Research results. The presented article actualizes the issues of social and investment development of Russian regions in the context of the ecological environment. Based on modern ecosophical ideas about the ecological environment as a constituent factor in the development of human capital, the

${ }^{1}$ Исследование выполнено в рамках гранта Президента РФ для государственной поддержки молодых российских ученых - докторов наук (МД-1493.2020.6) на тему «Ресурс исторической памяти в системе институциональных параметров социально-инвестиционного развития и обеспечения культурной безопасности региона». 
как конституирующем факторе развития человеческого капитала формируются основной вектор и способы освоения социальных инвестиций. Определяя экологическую среду как интегрированность условий комфортного проживания, здоровья, отдыха, авторы статьи ориентируются на интерсубъектные отношения в регионе, связанные с формированием экологической культуры и экологического дискурса. Результирующим моментом является предложение стратегии концентрации ресурса для социальноэкологических проектов в регионах с достаточными стартовыми площадками.

Перспективы исследования заключаются в разработке концептуально-методической базы социально-инвестиционного управления регионами.

Ключевые слова: экологический фактор; социально-инвестиционное развитие регионов; человеческий капитал; экологические риски; экософия main vector and ways of developing social investments are determined. Defining the ecological environment as the integration of conditions for comfortable living, health, recreation, the authors of the article are guided by intersubjective relations in the region associated with the formation of ecological culture and ecological discourse. The resulting moment is the proposal of a resource concentration strategy for social and environmental projects in regions with sufficient launch sites.
Prospects of the study are in the development of a conceptual and methodological framework for social and investment management of regions.

Keywords: environmental factor; social and investment development of regions; human capital; environmental risks; ecosophy

\section{Актуальность}

Экологическая проблематика становится традиционной в социологическом дискурсе регионального пространства. Этот тренд формируется под влиянием двух взаимосвязанных и взаимозависимых факторов. С одной стороны, российские регионы характеризуются различиями в состоянии экологической сферы по природно-климатическим, ресурсным и культурно-историческим основаниям, что продуцирует дифференциацию по социально-экономическим и социально-психологическим показателям. С другой стороны, уровень человеческого капитала в региональном развитии определяется показателями социального здоровья, социально-территориальной мобильности населения, для которого свойственно стремление к внутренней или внешней миграции с целью закрепления в более благоприятной для жизнедеятельности экологической среде.

Таким образом, экологическая проблематика значимо расширила рамки с конца 90-х гг. ХХ в. в гуманитарной мысли, где уже не оспаривается статус социальной экологии и экософии в рамках интеграции концептуального и социально-инструментального анализа. В этом смысле важно подчеркнуть, что в контексте глобализации экологических проблем, роста интереса к зеленой экономике и культуре экологии 
очевидно, что требуется разделение реальных социально-экологических рисков, ставящих под угрозу социальное воспроизводство общества и экологических мифов, порождаемых групповыми интересами на уровне государств и сообществ.

С этой целью требуется обращение к социально-философской рефлексии как совокупности знаний и установок, направленных на выявление динамики современных социальных процессов, в которых экологический фактор обретает самостоятельное значение. В развитии российских регионов, как подчеркивалось выше, экологический фактор выражается в различных сферах социально-политической и социальноэкономической жизни, но главное - дифференцирующее влияние экологии на состояние и перспективы регионального развития на то обстоятельство, что социально-экологические показатели опережают социально-экономические по анализу и оценке качества жизни в регионах и в настоящий период корректируют устоявшиеся схемы дифференциации регионов.

Другими словами, экологическая среда как пространство проживания населения регионов характеризуется потенциальными возможностями и рисками, когда речь заходит о росте влияния экологической среды на социально-инвестиционный и социально-инновационный климат в регионе и когда экологические образы региона определяют выбор социальных инвесторов и стратегию обеспечения государством социально-экономического развития региона. Экологические риски усиливают трансакционные издержки в социальном развитии регионов, поскольку негативный экологический фон означает рост расходов на мониторинг, профилактику и нейтрализацию последствий кризисных явлений в региональном пространстве, в той же степени следует учитывать дополнительные расходы на страховку от экологических рисков, возмещение дефицита демографических ресурсов в условиях усиления миграционных потоков в региональном пространстве (Public Administration and Regional Management in Russia ..., 2020).

Особенность дифференциации российских регионов заключается в том, что богатые регионы характеризуются повышенными экологическими рисками, что объяснимо в контексте использования ресурсной модели экономического развития, требований к адаптации населения к неопределенности, возникающей как результат влияния экологических катастроф. В этом аспекте актуальным становится выбор методологии исследования, имеющий, несомненно, междисциплинарный характер, но работающий в социально-философском дискурсе, направленном на 
определение объективных и субъективных факторов экологической среды в региональном пространстве российского общества.

\section{Методология исследования}

Актуализируемая в данной статье цель исследования определяется как совокупностью внешних и внутренних факторов, социальнопрактических запросов в российском обществе на развитие оптимальной экологической среды как необходимого условия консолидации регионального пространства, так и логикой развития социально-философской мысли, содержащей поиски и определения метаметодологии экологических изысканий. В этом контексте показательно развитие самостоятельных направлений социально-философской мысли, характеризующихся не только освоением новых предметных схем, но и выработкой теоретико-методологических схем, способствующих внесению ясности в содержание социально-экологической проблематики, в том числе и на региональном уровне (Кармадонов, 2008).

Учитывая тот факт, что регион относительно недавно стал предметом социально-философского анализа, что, в принципе, не преодолен политико-административный подход к политике региона, важно выявить социально-философские основания анализа экологической среды как формы социальной организации и самоорганизации регионального пространства. Неопределенность перевода экологической проблематики на язык социальной философии содержит ограниченность в понимании реальных фактов и событий, отражающих события экологической среды. Действительно, в условиях «радикализации» экологической проблематики требуется отклонение от идей экологического алармизма и вместе с тем отказа от схемы «Россия - страна неисчезающих ресурсов». Схемы действующих социально-экологических практик до сих пор направлены на эксплуатацию экологической среды, и это обстоятельство влияет на субъективный мир россиян, в котором экология воспринимается как важный, но работающий только в контексте отложенного будущего элемент. Аргументация, приводимая участниками дискуссии о состоянии экологической среды в российском обществе, требует согласия по основным вопросам и осознания безальтернативности экософии как социально-философского знания, содержащего теоретико-методологический инструментарий, анализирующий экологическую среду с помощью соотнесения с реальными социальными практиками.

Социальная эпистемология, интенсивно разрабатываемая на современном этапе российской социально-философской мысли, рассматривая экологическую проблематику культуры и философии, исходит из 
нового понимания субъекта и предмета познания (Социальная эпистемология ..., 2010). Натуралистическое понимание, соответствующее духу XX в., строилось по варианту неклассической философии, согласно которому экология становилась гуманитарной мыслью, но при этом не реализовывалась идея диалога человека и природы. Следствием являлась уверенность в том, что благодаря новым технологиям человек перестанет приносить ущерб природе и переориентируется на контроль и коррекцию природных процессов.

Реально экологические проблемы связаны с убеждением в возможности получения истинного знания, отсюда проистекает требование к теоретизации экологической среды. Между тем происходящие в экологической сфере процессы, особенно на уровне регионального пространства, испытывают, как правило, «цейтнот времени», нуждаются в ситуативных решениях, где эпистемологический анализ представляется абстрактным.

Таким образом, рефлексия экологической среды объективно обращается на мониторинг рисков, а возможности, связанные с социальноинвестиционным развитием регионов, переносятся в область социального проектирования, проявляются в форме должного, а не сущего. Экософия как синтетическое, социально-философское знание признана восполнить указанный пробел, так как направлена на формирование философии и культуры экологической среды. Очевидно, что в условиях роста рисков экологического характера региональное сообщество нуждается в системе управления экологическими рисками, а на массовом уровне - в формировании у населения интолерантности к экологическим нарушениям и преступлениям. Вероятно, для социально-философской рефлексии данной темы экософский подход, сочетающий процедуры системного и институционального анализа, субъектно-деятельностных и социально-диспозиционных норм, является предпочтительным как выбор теоретической схемы исследования.

Это обязывает к тому, что экологическая среда является не только результатом социально-практической деятельности, но на уровне экософии в него включается ее история, сам процесс получения данных о состоянии экологической среды, реализуется социально-ценностный аспект, когда экологическая среда рассматривается не в качестве ресурса экономического развития, логики целесообразности - важными являются сохранение и расширенное воспроизводство разнообразных экологических систем. В российском обществе на уровне сохранения традиций моногородов и индустриальной экономики экологическая сфера определялась с точки зрения минимизации затрат на ее сохранение (массовое 
насаждение тополя в советских городах как неприхотливого по условиям ухаживания растения из-за якобы высокого эффекта полезности в очистке воздушной среды) и нахождение решений, связанных с диструктивными последствиями промышленной деятельности в пользу «жертвования» здоровьем населения (Майснер, 2020).

Из этого следует, что социально-философский анализ экологической среды определяет ее уникальность на региональном уровне и одновременно всеобщность экологических проблем для российского общества. Главное, что объединяет эти два требования, есть необходимость сведения в точку познания логики действующего субъекта, который в идеале обязан опираться на принципы экософии, идеал гармонии человека и экологической среды, когда экологическая среда становится социально-инвестиционной, когда логика интересов регионального социума определяется вкладыванием усилий и средств в социальноинвестиционное развитие в той же степени, как это характерно для роста человеческого капитала в регионе на основе повышения ресурсоспособности в сферах образования, здоровья, спорта, культуры (Воденко, 2020).

\section{Результаты исследования}

В настоящий период становится ясно, что социально-инвестиционное развитие, которое является безальтернативным фактором для российских регионов, испытывает как сложности на уровне стратегии финансирования, когда в условиях углубления социально-экономического кризиса наблюдается сжимание ранее намеченных проектов на региональном уровне, так и проблемы несинхронизированности, асимметричности действий, направленных на включение экологической сферы в возможности социальноинвестиционного развития.

Внешне наметился поворот к экологии, особенно в сфере сохранения культурно-исторического наследия, развития туризма, стратегии поддержки малых городов России, что позволяет надеяться на реализацию постепенных шагов в этом направлении. Но если говорить по существу, нерешенными остаются вопросы, каким должно быть место и роль экологической среды в региональном сообществе, какие приоритетные задачи следует решать и какими средствами.

В настоящее время ситуация в этой области выглядит следующим образом.

По внешним показателям наблюдается модернизация критериев состояния экологической сферы как следствие включенности в глобальные зеленые стандарты. Нынешняя структура информирования в стране об экологических проблемах немногим отличается от существующих в 
остальном мире. Российские СМИ актуально освещают и дают анализ экологической ситуации, но с тем акцентом, что на первый план, как правило, выступают природные и техногенные риски (наводнения, лесные пожары, загрязнения водоемов). Таким образом, в обществе формируется экологическая тревожность, но она не обретает характера интолерантности к экологическим рискам. В конкретных регионах на уровне администраций и лоббистов приучают население к мысли, что ухудшение экологической ситуации является неизбежной платой за сохранение рабочих мест и поступление налогов в региональный бюджет. Данная тенденция отчетливо проявляется в Сибири и на Дальнем Востоке, где деятельность экономических монополистов, российских корпораций, интегрированных с глобальным капиталом, является по существу «внутренней колонизацией». В последнее время по реальным показателям произошло сокращение расходов на решение экологических проблем на региональном уровне в $1,5-2$ раза.

Согласно мониторингу сложившейся ситуации, проявляется правило приоритета первичной обработки, где российские корпорации играют на глобальном рынке путем снижения трансакционных издержек на сохранение экологической среды, и намечены проекты расширения добычи невозобновляемых ресурсов (уголь, лес), как показывает пример Хакасии, Красноярского края, Кемеровской области. Парадоксально, что электроэнергия, призванная развивать вторичное производство и чистую энергетику, включена в этот процесс в качестве инструмента деградации экологической сферы (строительство новых гидроэлектростанций с массовой вырубкой леса для экспорта дешевой электроэнергии в соседние государства). Все эти обстоятельства приводят к выводу, что экологическая среда измеряется по природно-ресурсным показателям и соответствующим образом не определяет логику социально-инвестиционного развития регионов, где в альтернативном варианте накопленные ресурсы от освоения природных богатств должны конвертироваться в развитие социально-инвестиционной сферы, которая и определяет переход региона к экономике возобновляемых ресурсов. В этом контексте узнаваем и полезен зарубежный опыт развития регионов с аналогичными природноклиматическими и природно-ресурсными показателями (Норвегия, Китай, Канада). Так, для Дальневосточного региона, где стремятся к реализации программы социально-экономического развития на основе «дальневосточного гектара», очевидно, что практика привлечения населения на землю не может дать гарантированно высоких результатов, так как аграрный сектор, создавая условия экономической суверенности, не может являться локомотивом социально-инвестиционного развития в реги- 
оне. Что здесь упущено в контексте экософского подхода? Очевидно, что отсутствуют внутренние показатели состояния экологической среды в рамках определения возможностей и рисков, возможности фиксируются экзистенционально: решающими факторами считаются демографический рост, обеспеченность земельными угодьями, развитость логистической структуры. Но, с точки зрения перспектив социальноинвестиционного развития регионов, не определяются возможности сохранения социального здоровья, рекреационной сферы, достаточной плотности информационных коммуникаций, возможности внутрирегиональной миграции. Обобщающим результатом является сохранение тенденций переезда населения из сельской местности в локальные мегаполисы (Хабаровск, Благовещенск, Чита).

Между тем описываемая ситуация позволяет извлечь уроки для социально-инвестиционного развития других российских регионов, где, разумеется, необходимо создание региональных матриц развития и определение универсальных смысловых констант данного процесса. Как отмечают исследователи в сфере социальной эпистемологии, мы имеем дело с разного рода типами теоретических и прагматических аргументов. Это выражается в том, что теоретические аргументы интерпретируются на уровне логики намерений, а прагматика заключается в принятии частичных решений. Идеология «дальневосточного гектара» является образцом прагматической аргументации, в которой территория необоснованно отождествляется с землей, представляющей собой результат возделанности, сложившейся инфраструктуры, культуры земледелия.

Наблюдается неинтегрированность экологической сферы в рамках создания комплексов социально-инвестиционного развития регионов. Южнороссийский регион в этом смысле работает также по логике внешних показателей, в которых приоритетными являются земельные и водные ресурсы. Острая дискуссия по поводу состояния южнороссийских водоемов (Азовское море, реки Дон и Кубань) показывает понимание наложившихся экологических проблем, при этом предлагаются технологические и запретительные решения (приостановка промышленных производств). В таком случае о перспективах социальноинвестиционного развития регионов не говорится. Заметим теперь, что консенсус относительно целей и способов социально-инвестиционного развития не достигнут. Исследуя экологическую сферу как аналитическое «сущее», можно говорить о том, что проявляется принцип конвенционализма, стремления к согласованию позиций заинтересованных сторон, но в силу неопределенности целей социально-инвестиционного развития регионов содержащего постоянную ревизию достигнутых со- 
глашений (показательна судьба строительства Николаевского гидроузла в нижнем течении реки Дон).

Очевидно, что экологическая среда в региональном пространстве до сих пор воспринимается как совокупность природных факторов, тем временем истинность сложившейся ситуации заключается в ее осмыслении как стратегического фактора роста человеческого потенциала. В этом смысле в России пока не разработаны эффективные меры по включению экологической среды в качество жизни населения, соответственно, социально-инвестиционная составляющая экологической среды остается неясной. В лучшем случае при следовании моде на зеленую экономику и зеленую технологию речь ведется об изменениях существующих экономических схем, но этого явно недостаточно. На примере внедрения элементов зеленой технологии в отдельных региональных сегментах (Татарстан, Подмосковье, Псковская и Калужская области) мы видим, что это не приводит к мультипликативному эффекту синхронизации экономического и социального роста региона.

Социально-инвестиционная проективность в регионах основывается на ожиданиях по созданию новых рабочих мест в прогрессивных производствах, интересах социально активного населения к вложению в образование, профессиональный рост, здоровье. Однако особенность регионального развития России состоит в том, что масштабные социальноинвестиционные проекты во многом зависят от позиции частных и государственных (полугосударственных) корпораций. Отказ владельца «Северстали» А. Мордашова от реализации проекта по производству труб для нефтегазовой отрасли в ХМА вызвал вначале «тихую панику», но затем мы наблюдаем рост недоумения и осуждения в адрес строптивого бизнесмена, поскольку данный проект имел социальную направленность, не только позволял обеспечить 500 новых рабочих мест, но и значимо расширял региональную налоговую базу, что важно в условиях развития социальной инфраструктуры на Севере, до сих пор испытывающем последствия оптимизации демографического ресурса путем внедрения вахтового метода. По крайней мере, претензии к А. Мордашову не связаны с экологическим фактором, с тем, что для ХМА строительство трубного производства экономически целесообразно. Явные преимущества имеет система глубокой переработки лесоматериалов и восстановление природных комплексов. Здесь нельзя ограничиться интересом к традиционным промыслам коренных народов (охота, рыболовство) и стараться произвести впечатление путем создания экопарков.

Вероятно, это лучше, чем ничего, но смысл реализуемой в статье идеи состоит в том, что экологическая среда должна стать сферой оби- 
тания и развития человека, т. е. выполнять социально развивающую миссию. Это означает, что в социально-инвестиционном развитии регионы стоят перед выбором стратегии экокультуры, направленной на то, чтобы решить двуединую задачу: с одной стороны, реконструировать экологическую среду, нейтрализовать риски здоровья населения, ибо в противном случае возрастают трансакционные издержки в форме непреложного роста расходов на здравоохранение; с другой - внимание к экологии, главное - мобилизация населения на защиту окружающей среды является фактором привлечения и внутренних, и внешних инвестиций. Внутренние инвестиции связаны с работой малого и среднего бизнеса, с освоением ими экосберегающих технологий. Внешние - с повышением планки налогов для корпораций как основных пользователей природных ресурсов и иностранных инвесторов, группы бизнесменов, сделавших выбор с целью по соображению «первопроходства» в России создать стартовую площадку для своего эколого ориентированного бизнеса.

Здесь важно, основываясь на методологии исследования, выявить субъекты социально-инвестиционного развития, включающего экологическую среду. Следует отметить, что в настоящий момент мы можем констатировать состояние неполной субъектности в этой сфере. Региональные власти, региональная элита, работающая по матрице бизнес власть, слабо ориентированы на принцип совместного решения вопросов социально-инвестиционного развития с заинтересованными группами регионального социума (бизнес-группы, общественные организации, молодежные движения). Сложность состоит в том, что, согласно социологическим исследованиям, общественный некоммерческий сектор в российских регионах только на 10-15 \% ориентирован на экологическую проблематику и к тому же страдает от дефицита экспертных кадров, способных через процедуры социальной диагностики определить возможности развития экологической среды для социальноинвестиционной траектории региона. Для отношений с региональной властью бизнес-группы лоббируют установление доверия в рамках формальных и неформальных обязательств, в большей степени финансовых и экономических проблем (в частности, со сферой кредитования) (Захарова, 2020).

Через призму сохранения бизнеса в нынешних кризисных условиях экологическая среда воспринимается как ограничительный фактор, так как ассоциируется с запретительными практиками ввода производств, якобы наносящих вред окружающей среде. Особенно это касается старых регионов России, где резкое ухудшение экологической ситуации (Архангельская область) вынуждает осторожно относиться к внешним 
проектам, направленным на накопление в регионе рискогенных ресурсов (отходы атомной промышленности, логистика бытового и промышленного мусора, перенос вредных производств из столичного региона на периферию). Таким образом, создается парадоксальная ситуация, когда региональный бизнес действует исходя из группового интереса «отказа» от экологии. Что же касается общественных и молодежных объединений, нельзя обольщаться мыслью, что в ближайшее время возникнет экологическое движение, объединяющее организации различного профиля «под зонтиком» экологии. Означает ли это, что вопросы, поднимаемые в статье, носят сугубо теоретико-конструктивный характер, что в реальности экософская проблематика не является концепцией, а состоит из совокупности благих положений и проектов? А в силу того, что в России намечается тенденция огосударствления экономики, что корпорации в стратегически важных отраслях экономики относятся к сфере влияния государства (полный или блокирующий пакет акций), речь идет о том, чтобы установить экологические нормативы, обязательные к исполнению в регионах, в целях стратегии поддержки социальноинвестиционного развития (Кривопусков, 2020).

Период становления социально-философского направления в экологической проблематике вступил в завершающуюся фазу, и в этом смысле представители экософии уверенно конкурируют и сотрудничают с экспертами в региональной проблематике. Если еще в 2007 г. было заявлено, что в числе основных факторов развития регионов на первое место выходил потенциал перерабатывающей промышленности, через десятилетие российские регионы характеризуются поворотом к социальноинвестиционному развитию как альтернативе стратегии «вторичной модернизации» (Столицы и регионы в современной России ... , 2018).

Очевидно, что изменения глобальных стандартов, осознание глобальных экологических вызовов и новые требования к промышленному производству влияют в качестве импульса на региональное развитие. Инвестиционный климат определяется состоянием экологической среды и экокультурой регионального социума, что расширяет возможности социально-инвестиционного проектирования в региональном пространстве: формирование представлений об экологической среде уже стало значимым социальным фактом. Снижается доминанта экономикоцентристского мышления, что являлось следствием внедрения рыночных принципов утери или изменения действовавших социальных норм. Что является недостающим звеном в концептуализации экологической сферы как фактора социально-инвестиционного развития региона? На первый взгляд, есть отставание в том, что закрепилось в контексте социологической 
мысли, в том, что социальная философия отстала в рефлексии региональной проблематики, квалифицируя ее как нефилософскую. Если придерживаться такой позиции, то в лучшем случае социальная философия на уровне экософии сосредоточена на человеке, но, отстаивая эту благую мысль, следует помнить о том, что мы имеем дело с конкретным человеком, субъектом социального действия (Ахметова, 2020).

Следовательно, требуется деобъективация экологической среды, ее познание с точки зрения результатов интерсубъектного взаимодействия, трактовки данной проблемы путем вывода из натурализма. Рассматривая выведенные в процессе нашего анализа теоретические сложности, мы можем сказать, что они обусловлены существующей зависимостью между идеально типическими конструкциями и идеями в смысле практической и теоретической направленности. Идея экологической среды как «обитания и развития человека» может быть постигнута только путем анализа актуальных идеально типических конструктов, которые, однако, в российских регионах не сложились иерархически. То есть мы не можем с уверенностью сказать, что есть показатели, позволяющие дифференцировать регионы по состоянию экологической среды. Хотя сделано немало для критической оценки накопившихся экологических рисков, это не означает, что единственным выходом из сложившейся ситуации является четкое разведение идеи экологической среды как социально-ценностного ориентира, содержащего возможности экологического консенсуса в обществе, и действительности экологической сферы, определяемой существующими социальными практиками. Здесь важно перейти от оценочных суждений, чем грешат современные социально-экологические экспертизы, к идеальному типу, индифферентному к специфическим региональным обстоятельствам и, главное, ориентированному на стратегию поддержки возможностей социально-инвестиционного развития региона (Тополева, 2019).

Тем более речь идет о том, что в современных условиях социальные инвестиции в региональное развитие определяются следующим: здоровая и комфортная экологическая среда является результатом целенаправленной человеческой деятельности, центр тяжести переносится на межсубъектные отношения. Иными словами, необходим диалог внутри регионального пространства, определяющий согласие по поводу того, на что и как будут использоваться инвестиционные проекты. Вероятно, при ориентированности на создание индустриально-территориальных кластеров по схеме реиндустриализации экологический аспект подвергается риску, и происходит возврат к идеологии индустриальной мобилизации прошлого времени. Однако в условиях поворота к зеленой экономике и зеленым технологиям экологи- 
ческий дискурс, определяющий региональное развитие как антропоцентристское, становится реальностью, а не мечтой.

Переосмысливается парадигма регионального развития, которое является социально-инвестиционным, поскольку направлено на приумножение человеческого капитала региона на основе человекосбережения. В альтернативном варианте проявляются известные изъяны избыточных затрат на систему медицинского обслуживания, связанную с профилактикой болезней индустриального века, созданием систем замкнутого технологического цикла, реконструкцией земельных угодий и необходимостью стимулирования восполнения трудовых ресурсов на основе внутренней или внешней миграции. Нельзя сказать, что социально-инвестиционное развитие в регионе начинается с чистого листа, для социально-экологического проектирования требуется определенная стартовая площадка, и в этом контексте российские регионы находятся в неравных условиях (критерием дифференциации является актуальное состояние экологической среды). Но очевидно, что направленность социальных инвестиций характеризует готовность субъектов регионального развития мыслить и действовать экософски.

\section{Заключение}

Актуализируемая в статье проблематика не является данью моде: стремясь превратить российскую экономику в конкурентную, имеющую стратегическую основу для социального развития, результаты и последствия, мы обязаны осознавать, что, во-первых, успехи всей страны зависят от положения дел в регионах (это является азбучной истиной, но почему-то забывается), что какие бы смелые проекты и какие бы финансовые затраты ни предпринимались в рамках Садового кольца, это будет иметь результатом рост дистанции между регионами и столицей, способствовать накоплению экологических рисков внутри метрополии (перенаселенность, загрязнение воздуха и воды, сбои в работе социальной инфраструктуры). Вовторых, для российского общества наступили времена, когда дальнейшая деградация регионов становится «красной линией», т. е., не определяя задачи регионального развития по формально-логическим критериям, необходимо запустить механизмы выборочного социально-экологического проектирования и в регионах, где сконцентрированы необходимые для социально-инвестиционного развития ресурсы, включить экспертное сообщество, которое, действуя в реальных условиях, в состоянии мобилизовать региональное сообщество на принятие решений, определяющих будущее как обусловленное человеческим потенциалом. 
Население региона обязано тратить деньги на местах, а не направлять доходы на социальные инвестиции в других регионах (как это происходит на северных территориях). Но в этом контексте индикатором качества жизни становится отношение населения к своему региону, к оценке не только социально-экономического состояния и перспектив социального развития, но и состоянию экологической среды, что подразумевает способность мыслить и действовать экологически, а на уровне управления - ориентироваться на экософскую рефлексию.

\section{Литература}

Ахметова Д. 3. «Человек экологический» в эпоху цифровизации // Высшее образование в России. 2020. Т. 29, № 5. С. 117-126.

Воденко К. В. Историческая память в социально-гуманитарном дискурсе: многообразие мнений и подходов // Вестник ЮжноРоссийского государственного технического университета (НПИ). Серия : Социальноэкономические науки. 2020. № 4. С. 5-13.

Захарова В.А. Перспективы развития экологического поведения российской молодежи в контексте «поздней» современности // Вестник Южно-Российского государственного технического университета (НПИ). Серия : Социально-экономические науки. 2020. № 6. C. $45-53$.

Кармадонов О.А. Эффект отсутствия: культурно-цивилизационная специфика // Вопросы философии. 2008. № 2. С. 29-41.

Кривопусков В. В., Месхи Б. Б. Социальноинвестиционная модель регионального управления как инструмент социально-экономического развития территории // Вестник ЮжноРоссийского государственного технического университета (НПИ). Серия : Социальноэкономические науки. 2020. № 5. С. 106-111.

Майснер Т. Н. Экологическая безопасность городского пространства: методологическая модель социально-философского исследования // Гуманитарий Юга России. 2020. T. 9, № 4. C. 189-199.

Социальная эпистемология: идеи, методы, программы / под ред. И.Т. Касавина. М.: Канон+, 2010. 712 c.

Столицы и регионы в современной России. Мифы и реальность пятнадцать лет спустя / под ред. М.К. Горшков. М.: Весь мир, 2018. 312 с.

\section{References}

Akhmetova, D.Z. (2020). «Environmental man» in the era of digitalization. Vyssheye obrazovaniye v Rossii, 29, 5, 117-126. (In Russian).

Vodenko, K.V. (2020). Historical memory in social and humanitarian discourse: diversity of opinions and approaches. Vestnik Yuzhnorossiyskogo gosudarstvennogo tekhnicheskogo universiteta (NPI). Seriya: Sotsial'noekonomicheskiye nauki, 4, 5-13. (In Russian).

Zakharova, V.A. (2020). Prospects for the development of ecological behavior of Russian youth in the context of "late" modernity. Vestnik Yuzhno-rossiyskogo gosudarstvennogo tekhnicheskogo universiteta (NPI). Seriya: Sotsial'noekonomicheskiye nauki, 6, 45-53. (In Russian).

Karmadonov, O.A. (2008). The effect of absence: cultural and civilizational specificity. Voprosy filosofii, 2, 29-41. (In Russian).

Krivopuskov, V.V., Meskhi, B.B. (2020). Socio-investment model of regional governance as a tool for socio-economic development of the territory. Vestnik Yuzhno-Rossiyskogo gosudarstvennogo tekhnicheskogo universiteta (NPI). Seriya: Sotsial'no-ekonomicheskiye nauki, 5, 106-111. (In Russian).

Meisner, T.N. (2020). Environmental safety of urban space: a methodological model of socio-philosophical research. Gumanitariy Yuga Rossii, 9, 4, 189-199. (In Russian).

Social epistemology: ideas, methods, programs. (2010). I.T. Kasavin (Ed.). Moscow: Kanon + Publ. (In Russian).

Capitals and regions in modern Russia. Myths and Reality Fifteen Years Later. (2018). M.K. Gorshkov (Ed.). Moscow: Ves' Mir Publ. (In Russian). Topoleva, T.N. (2019). Regional develop- 
Тополева Т.Н. Региональное развитие: новые теории // Economics Juvenis scientia. 2019. № 6. C. 14-17.

Public Administration and Regional Management in Russia - Challenges and Prospects in a Multicultural Region / E.G. Popkova and K.V. Vodenko (eds.). Cham: Springer International Publishing AG, 2020. 567 p.

Для цитирования: Воденко К. В., Лабадзе O. Е. Экологическая среда в контексте развития социально-инвестиционной модели управления российскими регионами: потенциальные возможности и риски // Гуманитарий Юга России. 2021.5 (51). С.202-216. DOI 10.18522/2227-8656.2021.5.14

\section{Сведения об авторах}

\section{Воденко Константин Викторович}

Доктор философских наук, профессор, Южно-Российский государственный политехнический университет (НПИ) имени М.И. Платова

346428, Ростовская обл., г. Новочеркасск, ул. Просвещения, 132, e-mail: vodenkok@mail.ru

\section{Лабадзе Олеся Евгеньевна}

Кандидат социологических наук, доцент, Южно-Российский государственный политехнический университет (НПИ) имени М.И. Платова

346428, Ростовская обл., г. Новочеркасск, ул. Просвещения, 132, e-mail: efimowa.olesya@yandex.ru ment: new theories. Economics Juvenis scientia, 6, 14-17. (In Russian).

Public Administration and Regional Management in Russia - Challenges and Prospects in a Multicultural Region. (2020). E.G. Popkova and K.V. Vodenko (Eds.). Cham: Springer International Publishing AG.
История статьи: Поступила в редакцию - 23.08.2021 г. Получена в доработанном виде 04.10.2021 г. Одобрена - 15.10.2021 г.

\section{Information about authors}

\section{Konstantin Viktorovich Vodenko}

Doctor of Philosophical Sciences, Professor, Platov South-Russian State Polytechnic University (NPI)

132 Prosveshcheniya St., Novocherkassk, Rostov region, 346428, e-mail: vodenkok@mail.ru

\section{Olesya Evgenievna Labadze}

Candidate of Sociological Sciences, Associate Professor, Platov South-Russian State Polytechnic University (NPI)

132 Prosveshcheniya St., Novocherkassk, Rostov region, 346428, e-mail: efimowa.olesya@yandex.ru 